Z Rheumatol 2020 $\cdot 79: 446$

https://doi.org/10.1007/s00393-020-00817-z

Online publiziert: 15 . Mai 2020

(c) Springer Medizin Verlag GmbH, ein Teil von Springer Nature 2020

\title{
S. Blüml
}

Klinik für Innere Medizin III/Abteilung für Rheumatologie, Medizinische Universität Wien, Wien, Österreich

\section{Erratum zu:}

\section{Biologika und "small molecules" bei der rheumatoiden Arthritis}

Erratum zu:

\section{Z Rheumatol 2020}

https://doi.org/10.1007/s00393-020-

00766-7

In Tab. 2 des Leitthemenbeitrags „Biologika und ,small molecules' bei der rheumatoiden Arthritis“(Heft 3/2020; https:// doi.org/10.1007/s00393-020-00766-7), werden die für die rheumatoide Arthritis (RA) zugelassenen b(biologische)DMARDs („disease modifying antirheumatic drugs“) und tsDMARDs („targeted synthetic DMARDs“) dargestellt.

Hier fehlte in der tabellarischen Darstellung der im Artikel erwähnte TNF-
a-Inhibitor Certolizumab, neben Infliximab, Etanercept, Adalimumab und Golimumab.

Bitte beachten Sie die korrigierte - Tab. 2.

\section{Korrespondenzadresse}

\section{PD Dr. S. Blüml}

Klinik für Innere Medizin III/Abteilung für Rheumatologie, Medizinische Universität Wien Währinger Gürtel 18-20, 1090 Wien, Österreich stephan.blueml@meduniwien.ac.at

\begin{tabular}{|c|c|c|c|}
\hline „Mode of action" & Präparat & Zulassung für RA (EMA) & Biosimilars \\
\hline \multirow[t]{5}{*}{ TNF-a-Inhibitor } & Infliximab & + & + \\
\hline & Etanercept & + & + \\
\hline & Adalimumab & + & + \\
\hline & Certolizumab & + & - \\
\hline & Golimumab & + & - \\
\hline \multirow[t]{2}{*}{ IL-6/IL-6-Rezeptor-Blocker } & Tocilizumab & + & - \\
\hline & Sarilumab & + & - \\
\hline Kostimulationsblocker & Abatacept & + & - \\
\hline B-Zell-Depletion & Rituximab & + & + \\
\hline IL-1 Receptor antagonist & Anakinra & + & - \\
\hline \multirow[t]{5}{*}{ JAK-Inhibitor } & Tofacitinib & + & - \\
\hline & Baricitinib & + & - \\
\hline & Upadacitinib & + & - \\
\hline & Filgotinib & Bevorstehend & - \\
\hline & Peficitinib & Zugelassen in Japan & - \\
\hline
\end{tabular}

Die Online-Version des Originalartikels ist unter https://doi.org/10.1007/s00393-020-00766-7 zufinden. 